Journal Home Page:

http://perlinguam.journals.ac.za

\section{Per Linguam}

A Journal for Language Learning Tydskrif vir Taalaanleer

Keiko Koda. 2005. Insights into Second Language Reading: A Cross-Linguistic Approach. Cambridge: Cambridge University Press. pp 320.

The importance of successful second language reading is widely acknowledged. As yet, however, viable L2 models of reading have not yet been constructed. Part of the problem is that L2 reading competence needs to be demarcated clearly from general L2 linguistic proficiency. Towards this end, Koda's goal is to establish a complex and coherent conceptual foundation for research on L2 reading, within a quantitative or testable framework. Although this volume is not a classroom teaching manual, implications of research findings for classroom practice are explicitly alluded to in the first three parts and clearly drawn in the last part.

Second language reading research is a very complex area. Not only is there a need to differentiate between L2 and L2 reading processes and between orthographic and phonological knowledge and skills or strategies; but there is also a need to take account of the readers' prior literacy experiences and knowledge. As Koda says:

Reading is a multifaceted, complex construct in that it involves a number of component operations, each dependent on a wide range of competencies. Obviously, the complexity increases in L2 reading since, by definition, it involves more than one language. (p. iv)

As the title indicates, Koda's central premise is that reading involves at least two languages. Consequently, the key components of reading are explored through this cross-linguistic lens.

This volume is divided into four parts. Keiko Koda uses the two chapters in Part I to orientate the reader to basic concepts and constructs in L2 reading research, and outlines the theoretical underpinnings of L2 reading competence. Each of the chapters in Part II is devoted to a key component of reading ability: word recognition, vocabulary knowledge (both the role known vocabulary plays in reading successfully and how reading helps learners to construct vocabulary), intraword awareness and word-knowledge development, information integration in sentence processing, discourse processing (including the role of background knowledge, inference and coherence in comprehension) and narrative and expository text structures and comprehension. Part III explores the way in which connections are made during the dynamic interaction between the components of reading. Part IV is concerned with application of insights from reading research to practice. One of the chapters is about assessment of L2 reading and the other is about reading instruction.

In Part I: Theoretical Foundations, Koda alerts readers to her goal of establishing a systematic theoretical foundation that can be used to expand research into L2 reading research and facilitate innovation in second language reading instruction. She also outlines the 
organisation of the volume. Her frame of analysis is psycholinguistic. Within this frame, the main concepts and constructs are: reading competence, $L 2$ readers, $L 1$ and $L 2$ reading. Her definition of reading competence draws on multiple perspectives: the interactive cognitive view (decoding, text-meaning construction, and the assimilation with prior knowledge); the developmental perspective (sequential mastery of decoding and comprehension and their functional interdependence); and the gear theory (which emphasises that complexity varies according to reading purpose).

Since it would be impossible to discuss the research relating to all L2 reading cadres, she has elected to focus on cognitively mature individuals already literate in L1 (with some reference to other cadres of readers where necessary). Further, while acknowledging the important insights that L1 reading research offers, Koda argues that it is vital to give attention to 'the specific constituents that define L2 reading competence' since 'a clearer understanding cannot be obtained by simply extrapolating L1 precepts' (p. 8).

Her principal approaches are cross-linguistic analyses and competency dissection.

In Chapter 2 (Theoretical underpinnings) she describes the principal theories that inform her investigation. These are transfer theory (cross-language reading skills transfer); the connectionist theory (explanation of skill acquisition and performance improvement); component skills approaches (vehicle for contrasting components of reading competency and relative impact on L2 reading efficiency). She also draws on the developmental interdependence hypothesis, the linguistic threshold hypothesis and decoding as a source of individual difference. Her careful synthesis makes it clear L1 reading, L2 proficiency and L2 decoding make significant contributions to successful reading comprehension. At the same time she highlights the need to recognise that these three constructs are complex and distinct. A simple conclusion like limited L2 knowledge inhibits L2 learners from using their previously acquired L1 skills belies the complexity of each of these constructs and the interplay between them.

Part II: Essential Components should be of particular interest to those involved in working with low proficiency readers. As is noted in Chapter 3 (Word recognition), low proficiency readers are invariably slower and less accurate in a variety of word-recognition tasks (p. 39) and that their concern is more on word-level than on discourse-level processing. A finding that is likely to be less well known is that word recognition skills and oral language proficiency do not require the same underlying competencies.

Chapter 4 (Vocabulary knowledge) focuses on the precise relationships between vocabulary knowledge and reading comprehension. The research presented shows that the relation between vocabulary knowledge and reading comprehension is far more complex than is commonly assumed. Although reading comprehension and vocabulary knowledge are mutually interdependent, their functional relationship changes during the course of their evolution. In practice, many teachers tend to teach 'difficult words' before reading of a text is begun. This does not have much effect on long-term retention. A key research area that Koda identifies is on ways of enabling L2 learners to make full use of their 'inherent capacity for self-teaching' (p. 70) to promote their word learning skills.

Chapter 5 (Intraword knowledge and word-knowledge) identifies the weaknesses in research on the specific impact of Intraword knowledge (or sensitivity to phonological and morphological elements) and word-knowledge. What is widely accepted is that knowledge of 
morphological structure directly facilitates the capacity to spell and read and is furthermore a powerful predictor of reading success (p. 73). However, Koda's analysis and synthesis identify the need to give a fuller account of the conceptual framework so that more systematic research into word-knowledge acquisition through reading can be undertaken. Koda's firm statement that early L2 reading development (as in the case of L1) is fundamentally metalinguistic provides an important perspective: learners need to understand not just identify the way in which significant language units are mapped on to graphic symbols.

Chapter 6 (Information integration in sentence processing) is the densest chapter both in terms of the conceptual complexity of the content and the presentation. At the heart of the investigation is the knowledge that words gain meaning from being integrated into a pragmatic, semantic and linguistic context. What Koda reveals is that there is little research to sustain many common assumptions: one such is that there is a simple connection between the length of a sentence and reading problems.

In my view, Chapter 7 (Discourse processing) is the richest in the volume. Koda reveals that, whereas aspects like background knowledge and inference in L1 reading comprehension are fairly well researched, the same is not true of L2 reading comprehension. A particularly interesting line of research that Koda identifies is exploring the precise ways in which background knowledge, inference and text-information is constrained by limited linguistic sophistication (p. 153).

Chapter 8 (Text structure and comprehension) should be particularly useful to educationists in South Africa, where a text-based approach has been adopted. Koda skilfully demonstrate the complexity of the processes involved. As she shows using narrative texts, in particular, each of the text types requires genre-specific processes. Commenting on research into the relation between them, Koda argues, '[T]here is room to question whether L2 proficiency and text structure knowledge develop simultaneously in uniform, linear fashion among learners with diverse L1 backgrounds' (p. 178). Comprehension success seems to be substantially determined by the ability to activate appropriate knowledge bases and to assimilate new insights into relevant conceptions.

Part III: Looking at the Whole provides a holistic picture of reading. Chapter 9 (Individual differences) explores the research on the differences that occur in all aspects of reading. Koda's analysis reveals that the implications for developing L2 reading comprehension of the vast amount of research on this component are rather limited. There are exceptions such the fairly clear evidence that working memory provides cognitive resources for integrating information presented in sequence; it can influence just about all aspects of comprehension. Useful areas for research include extending the generalisability of findings (using a broader array of L1 backgrounds) and further clarification of the influence of the complex construct, working memory capacity.

The analysis in Chapter 10 (Strategic reading) provides an impressive analysis of the wideranging field of strategic reading despite the constraints of space: in this case, only 20 pages. Her synthesis of the findings presents a balanced picture of the value of research in this area and the gaps in it. An area of particular value in higher education would be an investigation into the ways in which strategy use varies in reading texts with contrasting linguistic and conceptual complexity. 
Part IV: Theory into Practice offers valuable pointers to incorporating theory into practice. In Chapter 11 (Comprehension Assessment), Koda begins by problematising L2 assessment of reading, which tends to be viewed as an integral part of L2 proficiency. Something of that emerges in the test constructed in South Africa by Chamberlain and Reyneke (1992) referred to in article 4 in this issue. Koda outlines the conceptual bases of assessment approaches and their implications for test design and development, assessment models in L1 and L2 instructional contexts and some assessment techniques. I found the succinct summary of the main issues in reading assessment particularly valuable. And her trenchant comment about the limitations of language-based reading assessment deserves serious consideration.

Language-based L2 reading assessment ... tends to measure information extraction and integration only in conceptually neutral texts, requiring meaning construction of familiar content only.

In the Chapter 12 (Comprehension instruction) final chapter, Koda sifts through the masses of information to identify ways of improving classroom instruction. She gives attention to the following areas: decoding, vocabulary knowledge, syntactic processing, text structure, main idea detection, and background knowledge strategies.

In refreshing contrast to the continuing binary phonics vs. whole language debates, Koda highlights the way in which the learner's ability to map information makes it possible to read new words 'through analogy and inference rather than by rote memory'. Learners need to pay adequate attention to the word's meaning while focusing on its sound. Therefore

(i) Students must acquire an explicit understanding of how their writing system works

(ii) Meaning extraction must be part of decoding training

(iii) Symbol-to-sound mappings must be practised in meaningful contexts

She adds a few caveats. One of them is about the dangers of adopting a particular training method: the reality is that learners have divergent cognitive and linguistic dispositions. Another is that a distinction must be made between teaching words and teaching how to learn words (p. 256)

This publication does have some shortcomings. Although Koda makes it clear that her perspective would be a psycholinguistic one, I think it a pity that there was no indication of how psycholinguistic elements are related to other critical elements in L2 reading such as sociolinguistic and affective factors or critical pedagogy. Ultimately, a holistic picture is vital. Another shortcoming is that there is not an index. A third is that at times the need to give attention to a very large resource base means that the text becomes very dense. But these criticisms are minor when viewed against the remarkable achievement of the volume Koda's detailed analysis and skilled synthesis of a wide range of current psycholinguistic research findings goes far beyond a survey; it offers numerous suggestions for systematic study and systematically insists on the need for a more complex view. Researchers, particularly those with a psycholinguistic perspective, should find it a very valuable resource. The cross-linguistic perspective seems to hold considerable promise as a means of understanding the L2 reading process more fully. L2 teachers and teacher educators could use it to interrogate current classroom practice and to adapt their instruction to the needs of 
E Ridge

individual learners. As Kado makes clear, best practice will not be found in the adoption of a single pedagogical method: L2 reading is far too complex for that.

Elaine Ridge 